
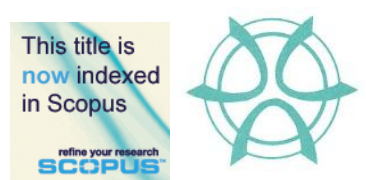

PLANNING MALAYSIA:

Urban Planning and Local Governance

Volume III (2014), Page 111- 126

\title{
EVALUATING THE EFFECTS OF ROAD GEOMETRICAL DESIGN TOWARDS SPOT SPEED DISTRIBUTION ON ARTERIAL ROAD
}

\author{
Noor Hafiza Mohd Maksid ${ }^{1}$ and Abdul Azeez Kadar Hamsa ${ }^{2}$ \\ ${ }^{1 \& 2}$ Kulliyyah of Architecture and Environmental Design \\ INTERNATIONAL ISLAMIC UNIVERSITY MALAYSIA
}

\begin{abstract}
Drivers travel at speeds they judge to be comfortably achievable in relation to the prevailing conditions and road geometrical design. The relationship between road geometrical design and speed of vehicles traveling in is very prominent. Speeds vary according to the perception of constraint imparted to the drivers by the road geometrical design. In a broader sense, these two factors are often interrelated with speed limits and road safety. The purpose of this study is to investigate how road geometrical design could influence the speed of vehicles on arterial road. Two roads with different geometric design were compared: arterial road with straight stretch and arterial road with curved stretch. The study was carried out by analyzing the speed characteristics between these two road stretches and it was discovered that vehicles traveling on straight road stretch tend to travel at higher speed than curved road stretch. The difference in the mean speed of the straight road and the curved road was tested for statistical significance by using t-test. The results show that there exists difference in the mean speed of the vehicles traveling at straight and curved road stretches. It was also found that the existing speed limit of the selected road stretches is lower than the 85th percentile speed. The 85 th percentile speed is a commonly used measure to decide speed limit on a road. The vehicles were traveling at higher speed along straight stretch of road than curved road stretch. Few recommendations on strengthening the enforcement and improving speed reduction measures are drawn to discourage drivers driving at high speed to make roads free from accidents.
\end{abstract}

Keyword: speed, road geometrical design, road safety, straight road, curve road

\footnotetext{
${ }^{1}$ Undergraduate Student at Department of Urban and Regional Planning, KAED, IIUM, Malaysia. Email: nhafiza@hotmail.com

${ }^{2}$ Associate Professor at Department of Urban and Regional Planning, KAED, IIUM, Malaysia. Email: azeez@iium.edu.my
} 
Noor Hafiza Mohd Maksid and Abdul Azeez Kadar Hamsa

Evaluating The Effects of Road Geometrical Design Towards Spot Speed Distribution on Arterial Road

\section{INTRODUCTION}

Speed is an important measure to evaluate safety of the road network. Speed is also an important transportation parameter because other than safety, it relates to time, comfort, convenience, and economics. According to Currin (2001), high speed carries high risk, whereas low speed is relatively safe. Traveling at a speed more than the speed limit is not recommended, as it could cause the drivers to lose control of their vehicles and cause fatalities, especially at winding roads. In Malaysia, accidents on roads are linked with the problem of inconsistencies in the operating speed. Driving at above the speed limit, uncertain weather conditions and drowsiness of the drivers are the three main causes of fatal accidents during the festive seasons (The Sun, 2009). A number of issues may be relevant with respect to the road safety aspect of a development proposal and in particular speed of vehicles. A study by Moore et.al., 1995 has documented an extraordinary strong association between speed and road traffic crash risk, the odds ratio for speed in excess of $84 \mathrm{~km} /$ hour is being almost 40 times higher than that for speeds below $60 \mathrm{~km} /$ hour (Petridou and Moustaki, 2000). A number of research has shown that the safest groups are the vehicles travelling at or below the $85^{\text {th }}$ to $90^{\text {th }}$ percentile speeds. A research by Elvik, et.al., 2004, has found that there is a very strong statistical relationship between speed and road safety and it is difficult to think of any other risk factor that has a more powerful impact on accidents or injuries than speed. The statistical relationship between speed and road safety is very consistent as when speed goes down, the number of accidents or injured road users also goes down in $95 \%$ of the cases. When speed goes up, the number of accidents or injured road users goes up in $71 \%$ of the cases (Elvik, et.al., 2004).

The U.S. Federal Highway Administration in 2005 has declared that nearly $30 \%$ of fatal vehicle collisions every year in the United States were taken place on curve alignment of the roads. About $83 \%$ of these crashes on winding roads were due to roadway departures from sliding, skidding or rolling over. All the causes, as mentioned above, for the vehicles which are running off the road namely sliding, skidding and rollover were caused by negotiating the curve at a very high speed. On the other hand, in Denmark, about $20 \%$ of all personal injury accidents and $13 \%$ of all fatal accidents were occurred on curves in rural areas; and in France, over $20 \%$ of fatal accidents on dangerous curves in rural areas (Herrstedt and Greibe, 2001). The reason for the accidents is the same as indicated earlier, where the drivers were negotiating the curve at a very high speed. In China, according to the accidents database by the Chinese Ministry of Transportation in 2009, 
26,292 road accidents were occurred on curved roads accounting for about $10 \%$ of the total accidents in 2008 . Additionally, 9,070 people were died and 36,112 people were severely injured in these accidents. The main cause of these accidents, again, is due to excessive vehicle speed (Chen et.al.). In a simple sense, these kinds of accidents were happened at road curves because of inappropriate speed of vehicles, traveling at a speed higher than the speed limit along that particular road. However, the inappropriate-speed theory can be applied to straight road as well, where drivers have the tendency to press the accelerator and generally increase the speed because of a greater feeling of well-being and sense of familiarity of the road, consequently increasing the accident risk. A survey conducted by Collins (2008) has identified, drivers, on average, would drive faster on a straight open road, followed by a straight road in bad weather, a bendy open road, a bendy road in bad weather, a straight road in the dark and, finally, a closed bendy road. Nonetheless, it is also shown that speed limits, if suitably selected, can help to reduce the speeds thus reducing the accident rates (Hobbs and Richardson, 1967).

In a nutshell, it is evident that there is a clear relationship between changes in speed and changes in road safety: the larger the change in speed, the larger the impact on accidents or accident victims. In relation to this statement, it can be seen that road geometrical design also has some influences towards the speed of vehicles, thus explaining about the close relationship between road geometrical design, speed, and road safety. This paper focuses on the relationship between speed of vehicles and road geometrical design, and explains how different road geometrical design can influence the speed of vehicles. This paper describes the measurement of speed characteristics of the vehicles at a specified location under free-flow traffic conditions prevailing at the time of the study.

\section{LITERATURE REVIEW}

\section{Spot Speed}

In moving traffic stream, each vehicle travels at a different speed. Thus, the traffic does not have a single characteristic value, but rather a distribution of individual speeds. Speed is generally qualified according to three main types: i) Spot speed, ii) Running speed, and iii) Journey speed.

Spot speed is speed at a certain spot on one part of road at certain time (Mohamed, 1993), defined as the average speed of vehicles passing a point. Spot speed study is designed to measure the speed characteristics at a 
Noor Hafiza Mohd Maksid and Abdul Azeez Kadar Hamsa

Evaluating The Effects of Road Geometrical Design Towards Spot Speed Distribution on Arterial Road

specified location under the traffic and environmental conditions prevailing at the time of the study. According to Khanna (2001), spot speeds are affected by physical features of the road for example pavement width, curve, sight distance, gradient, pavement unevenness intersections, and roadside developments. Other factors that could influence spot speeds are environmental conditions (like weather, visibility), enforcement, traffic conditions, driver, vehicle, and motive of travel.

The above statement is supported by Hobbs (1967), where he wrote that measurements of spot speeds show a wide distribution and many interacting circumstances serve to determine the particular speed which individual drivers adopt. These circumstances will include those peculiar to the driver himself (such as his psychological and physiological traits); those concerned with his immediate environment and those affected by the more remote environmental considerations of law enforcement, type of district, and public opinions. Mohamed (1993), Khanna (2001), and Hobbs (1967) further explained the main elements of immediate environment are type of vehicle, road alignment, cross section and surface, weather, speed limits, and volume. As we can see, there are several elements that are repeated, which shows that the authors have agreed on the common elements that could influence spot speed.

Mohamed (1993) and Garber (2001) have cited that spot speed data can be used for certain purposes. It includes, but not limited to:

h. Establishment of parameters for traffic operation and control and determination of existing roadway speeds, such as speed zones, speed limits (85th percentile speed is commonly used as the speed limit on a road), passing restrictions, and prioritisation of speed enforcement locations;

i. evaluate the effectiveness of speed enforcement programs such as use of different speed limits for passenger cars and trucks;

j. evaluate, identify or determine the adequacy and speed impact of roadway geometric characteristics, including horizontal and vertical alignment and general roadway features;

k. identify whether the roadway is in need of greater law, enforcement, or reconstruction;

1. determine speed trends and impact of traffic control devices (traffic signs, pavement markings, signals etc.);

$m$. evaluate the effects of speed on highway safety through the analysis of crash data for different speed characteristics; and

n. provide evidence to support or refute complaints of excessive speed. 
In conducting the spot speed study, the suitable place and time for conducting this study are the important elements to be considered. According to Mohamed (1993), before placing the equipment and enumerators, researchers should search for a suitable site to conduct the study. Based on the objectives of the study, among the sites that are often selected as study site are highway or road that is straight, even and wide; road segment that is located between two junctions in urban area; road accident site or area where signboard is proposed. In terms of the suitable time to conduct the spot speed study, Mohamed (1993) has suggested the time between 9.00 a.m. to 12.00 noon; 3.00 p.m. to 6.00 p.m.; and 8.00 p.m. to 10.00 p.m.; study duration of one hour and; at least 50 vehicles as samples.

\section{Road Geometrical Design}

Ashley (1994) and Khanna (2001) stated that the required geometric design of highway depends on the speeds that vehicles are traveling. The speeds that are anticipated on the road are generally the basis for planning appropriate road alignment. Therefore, during the design stage, appropriate speed along the highways shall be determined in advance. However, Hong and Oguchi (2005) provided a contrast view stating that speed of traveling vehicles is dependent upon the geometric design of the highways. These statements highlight that both road geometrical design and speed of the vehicles have symbiosis relationship - i.e., both dependent upon each other. Ashley (1994) also stated that the geometric design parameters of horizontal alignment such as bends and straights should fit the functions of road. It was considered that straight roads are the safest and most beneficial of all but subsequently the opinion has shifted towards horizontal curvature can be beneficial as well, provided it is designed appropriately. An example of this is the introduction of bends in highway to reduce speeds, as long straight stretches of road may encourage undesirably high speeds whilst also contributing to loss of concentrations due to monotonous alignment.

It is important to note that, when assessing the acceptability of the geometry of an existing highway, the design standards related to the 85th percentile speed should be relevant. For example, if a highway has a speed limit of $90 \mathrm{~km} / \mathrm{h}$, but it is considered that the actual 85 th percentile speed is greater than $90 \mathrm{~km} / \mathrm{h}$, then the required geometry should be assessed in relation to the higher observed design speed. It should always be remembered that the underlying factor for the standards of road geometry is highway safety (Ashley, 1994). Consequently, the vehicles observed in the 
Noor Hafiza Mohd Maksid and Abdul Azeez Kadar Hamsa

Evaluating The Effects of Road Geometrical Design Towards Spot Speed Distribution on Arterial Road

lower 15 percent are considered to be traveling unreasonably slow and those observed above the 85th percentile value are assumed to be exceeding a safe and reasonable speed (Texas Department of Transportation, 2012).

In this regard, road geometry shall be designed to suit the needs of it, and speed is one of the main elements that must be taken into consideration as road geometry and its design influence speed. Currin (2001), Ashley (1994) and Hobbs (1967) agreed that speeds may vary, but it depends on several factors that might affect it such as:

e. general variables - time, date, weather conditions, highway classification, lighting conditions etc.

f. road users - drivers, journey purpose, travel mode etc.

g. vehicles - type, make, year, vehicle conditions, external and internal features etc.

h. road environment - traffic control, traffic conditions, road design features, road surface, adjacent land use, special consideration etc.

On the subject of traffic lane, both Bateman (1948) and Khanna (2001) agreed that the minimum width of traffic depends upon the width of the motor vehicles and lateral clearance between passing vehicles which is considered safe. Mannering (2005) also mentioned that when lanes are narrower, adjustment is needed because narrow lanes and obstructions close to the travel lane could cause the traffic to slow as a result of reduced psychological comfort and limits on driver maneuvering and accident avoidance options.

\section{Highway Functional Classification}

Highways are classified according to their respective functions and in terms of character of the service they are providing. Highways and streets are primarily described as rural or urban roads, depending on the areas in which they are located. This primary classification is essential since urban and rural areas have different characteristics, especially those that are related to type of land use and population density, which significantly influence travel patterns (Garber, 2001). Garber (2001) also mentioned that all highway systems involve a hierarchical classification by the mix of access and mobility functions provided. There are four major classes of highways which include: 
e. Limited-access facilities

f. Arterials - principal arterials and minor arterials

g. Collectors - major collectors and minor collectors

h. Local roads and streets

For this study, only literatures related to arterial system are focused in this section. Arterials are the surface facilities that are designed primarily for through movement but permit some access to abutting land (Roess, Prassas. and McShane, 2004). One of the most significant characteristics of arterial roads is vehicles traveling at a speed 80 to $90 \mathrm{~km} / \mathrm{h}$. As listed by Garber (2001), arterials can be divided into two: major or principal arterials and minor arterials. The principal and minor arterials then can be divided into two more categories namely - for principal: urban principal arterial system and rural principal arterial system, and for minor, urban minor arterial system and rural minor arterial system (Garber, 2001). Urban principal arterial system is the system of highways serves the majority activity centers of the urban areas and consist mainly the highest-trafficvolume corridors. On the other hand, the rural principal arterial system consists of a network of highways that serves substantial number of interstate trips. Virtually all highway trips between urbanized areas and a high percentage of the trips between small urban areas are made on this system.

The urban minor arterial system includes streets and highways that are interconnect with and augment the urban primary arterials. This system serves trips of moderate length and places more emphasis on land access than the primary arterial system. As for the rural minor arterial system, Garber (2001) stated that this system of road boosts the principal arterial system in the formation of a network of roads that connects cities, large towns, and other traffic generators, such as large resorts. Travel speeds on these roads are normally higher than principal arterial system.

\section{OBJECTIVES AND RESEARCH METHODOLOGY}

\section{Objectives}

The following are the objectives of this study:

v. To identify existing road geometrical design elements of straight and curved arterial road segments.

vi. To evaluate the effects of road geometrical design of the selected road stretches on the speed of vehicles. 
Noor Hafiza Mohd Maksid and Abdul Azeez Kadar Hamsa

Evaluating The Effects of Road Geometrical Design Towards Spot Speed Distribution on Arterial Road

vii. To compare spot speed of traffic stream at the selected road stretches.

viii. $\quad$ To suggest measures in achieving stipulated speed limit by the road users.

\section{Background of Study Area}

The study area is a stretch of an arterial road namely KL Middle Ring Road (MRR2). MRR2 is a ring road that was built by Public Works Department to link neighborhood areas around Wilayah Persekutuan Kuala LumpurSelangor border. The spot speed survey station was located at two points as indicated by point $\mathrm{A}$ and Point $\mathrm{B}$ in figure 1. Point $\mathrm{A}$ is located at the curvature stretch of the road near Zoo Negara, and point B at the straight stretch of the road near a Petronas Petrol Station. Both points have the same road characteristics having three lanes in each direction measuring $3.5 \mathrm{~m}$ lane width and $10.5 \mathrm{~m}$ total width. The stretches of the selected road were dual carriageway and the road surface was asphaltic concrete.

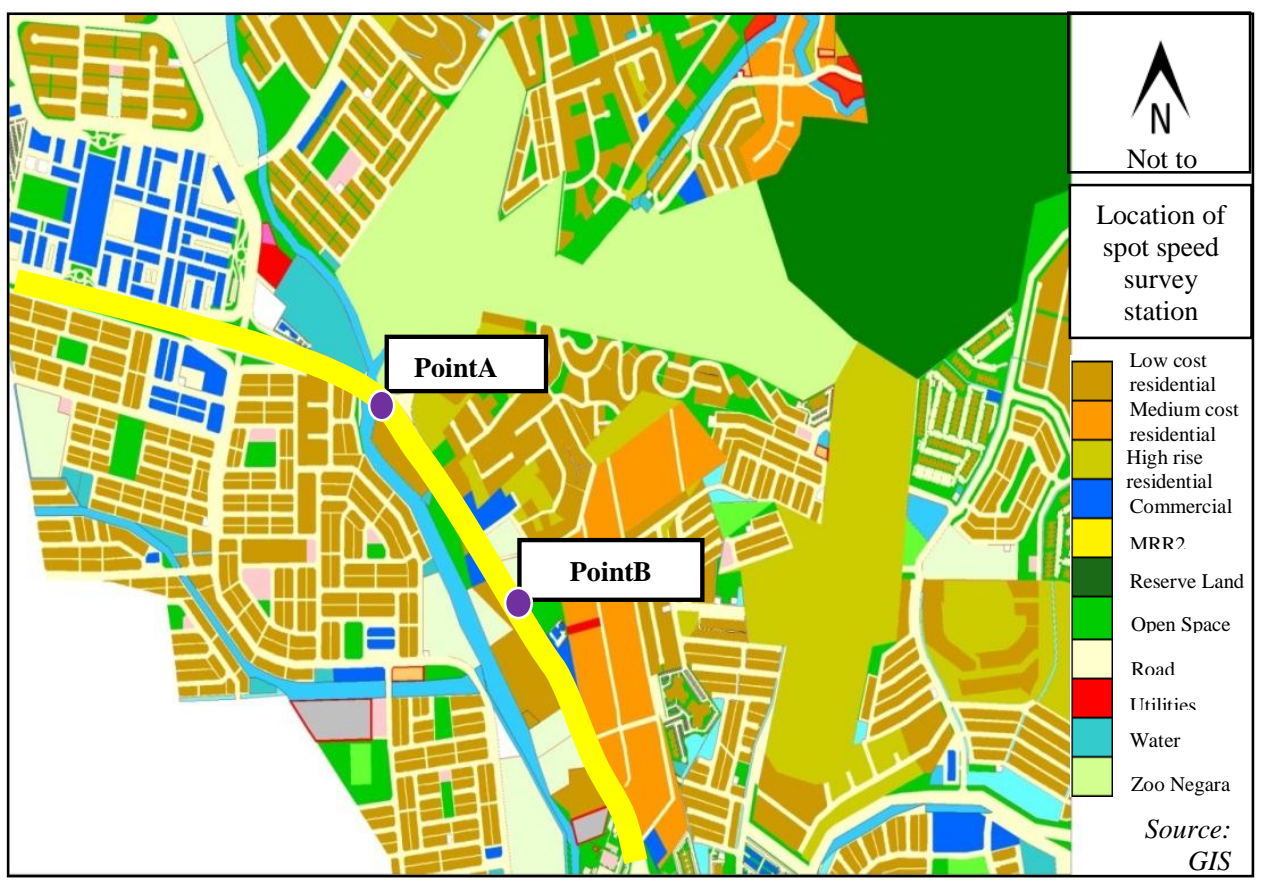

Figure 1 Location of Spot Speed Survey Stations 
PLANNING MALAYSIA

Urban Planning and Local Governance

\section{Sample Size and Sampling Method}

The geometric design elements covered in this study include the horizontal curve, width of the road, and available lanes. Besides, the other physical aspects such as the width of road median, width of road shoulder, and road surface were also considered. On the other hand, the spot speed survey was conducted on 100 vehicles (which is the selected sample size) passing at a point at each of the straight and curved road.

Systematic sampling method was applied to ensure that the samples were appropriately selected to represent the population. Only passenger cars were selected as the target vehicle because they represent the predominate mode of transportation along the selected road and other roads. The systematic sampling method was applied by selecting the first vehicle randomly and then every $5^{\text {th }}$ vehicle until the total sample size was reached. On average, the traffic volume on MRR2 was 180,000 to 200,000 vehicles per day (Ministry of Works, 2011). Data was collected during off-peak hour to measure the actual speed of vehicles during free-flow traffic.

\section{Method of Data Collection}

Data on roadway geometry such as horizontal curve, available lanes of the selected arterial road and road surface was observed. Pictures were taken to represent data on these elements by using a camera. Furthermore, the width of the road and its shoulder were measured using a laser distance meter device and a measuring tape. To measure spot speed, two points on the arterial road, one at the straight stretch and another at the curvature stretch were selected. In order to collect the data on spot speed, the enumerators have placed a radar gun at an appropriate location at the road side at a distance of minimum 10 meter from the selected vehicles. The radar gun was targeted at each selected vehicle to measure the spot speed of the vehicles.

\section{Method of Data Analysis}

The spot speed characteristics such as mean, median, standard deviation and percentile speed were calculated by using statistical analysis methods. T-test was used to test the statistical differences in mean speed of the vehicles at straight and curved stretch of the road. The calculation of t-test was conducted by using Minitab. Samples, mean, and standard deviation were filled in into Minitab prior to the calculation of the t-test. 
Noor Hafiza Mohd Maksid and Abdul Azeez Kadar Hamsa

Evaluating The Effects of Road Geometrical Design Towards Spot Speed Distribution on Arterial Road

\section{RESEARCH FINDINGS}

\section{Road Geometrical Design Analysis}

The road geometrical designs such as width and number of lanes were similar at the both selected road stretches. The width of the road is 10.5 meter with three lanes each direction, each measuring 3.5 meter wide. The width of this road is identical with that of the guideline requirements of an arterial road width (Ministry of Works, 2011).

For straight road, the width of each traffic lane is even. The road shoulder at the extreme left of the road is measured as 1 meter wide. The width of landscape and drainage reserve is 2.75 meter and 1.5 meter respectively (table 1). The median width of this road is 2.5 meter.

Similarly, the width of the curved road is also even for each of the three traffic lanes. The median is 2.5 meter wide. The width of landscape and drainage reserve is also 2.75 meter and 1.5 meter respectively. However, this road stretch has wider shoulder at approximately 3 meter. The normal, usable shoulder width that should be provided along arterial road is 3 meter (Ministry of Works, 2011).

Although both road stretches have no grades or vertical curvature, road with curvature, however, has super elevation. According to Ministry of Works, the maximum super elevation ratio that should be allowed for urban roads is 0.06 . Generally, the main differences between the two road stretches are horizontal curvature, width of shoulder and super elevation (table 1). Other than that, the road stretches are similar in terms of road geometrical design.

Table 1: Road geometrical design elements at straight and curved arterial road

\begin{tabular}{|l|c|c|}
\hline $\begin{array}{l}\text { Road geometrical design } \\
\text { elements }\end{array}$ & Straight road & Curved road \\
\hline Horizontal curvature & No horizontal curvature & Has horizontal curvature \\
\hline Width of road & $10.5 \mathrm{~m}$ & $10.5 \mathrm{~m}$ \\
\hline Total of lanes available & 3 lanes & 3 lanes \\
\hline Road surface & Asphaltic concrete & Asphaltic concrete \\
\hline Width of road shoulder & $1 \mathrm{~m}$ & $3 \mathrm{~m}$ \\
\hline Width of median & $2.5 \mathrm{~m}$ & $2.5 \mathrm{~m}$ \\
\hline Landscape corridor & $2.75 \mathrm{~m}$ & $2.75 \mathrm{~m}$ \\
\hline Drainage reserve & $1.5 \mathrm{~m}$ & $1.5 \mathrm{~m}$ \\
\hline Super elevation & No super elevation & Has super elevation \\
\hline
\end{tabular}


PLANNING MALAYSIA

Urban Planning and Local Governance

\section{Spot Speed Analysis}

The spot speed was measured at two different points, one at straight stretch and another at curved stretch, along Middle Ring Road 2 (MRR2). The sample size at each point of the road stretch is 100 . The modal speed at straight road was $68-74 \mathrm{~km} / \mathrm{h}$, but at curved stretch it was $76.5-82.5 \mathrm{~km} / \mathrm{h}$. The mean spot speed at straight road was $83.47 \mathrm{~km} / \mathrm{h}$ and at the curved road stretch, it was $73.92 \mathrm{~km} / \mathrm{h}$. The difference in mean speed between the two roads is $9.55 \mathrm{~km} / \mathrm{h}$ (table 2). It shows that drivers were driving at higher speed at straight road stretch than curved road.

Table 2: Spot speed characteristics at straight and curved road stretches

\begin{tabular}{|c|c|c|}
\hline Type of road & Straight road & Curved road \\
\hline No. of sample & 100 & 100 \\
\hline Mean speed & $83.47 \mathrm{~km} / \mathrm{h}$ & $73.94 \mathrm{~km} / \mathrm{h}$ \\
\hline Modal speed & $71 \mathrm{~km} / \mathrm{h}$ & $79.5 \mathrm{~km} / \mathrm{h}$ \\
\hline Median speed & $82.2 \mathrm{~km} / \mathrm{h}$ & $74.5 \mathrm{~km} / \mathrm{h}$ \\
\hline Standard Deviation & $12.87 \mathrm{~km} / \mathrm{h}$ & $12.10 \mathrm{~km} / \mathrm{h}$ \\
\hline $15^{\text {th }}$ percentile & $69.1 \mathrm{~km} / \mathrm{h}$ & $60.4 \mathrm{~km} / \mathrm{h}$ \\
\hline $85^{\text {th }}$ percentile & $96.2 \mathrm{~km} / \mathrm{h}$ & $85.4 \mathrm{~km} / \mathrm{h}$ \\
\hline
\end{tabular}

The median or 50th percentile speed at straight road stretch was $82.2 \mathrm{~km} / \mathrm{h}$ and that of curved road stretch, it was $74.5 \mathrm{~km} / \mathrm{h}$ (table 2). It indicates that half of the cars were travelled at a speed of $82 \mathrm{~km} / \mathrm{h}$ and below at straight road stretch and $74.5 \mathrm{~km} / \mathrm{h}$ at curved road stretch.

The standard deviation speed at straight road stretch was 12.87 $\mathrm{km} / \mathrm{h}$ and $12.10 \mathrm{~km} / \mathrm{h}$ at curved road stretch. Percentiles can be used to indicate the position of an individual speed in a group of vehicles. It is mentioned in the literature that the vehicles observed in the lower 15 per cent are considered to be traveling unreasonably slow and those observed above the 85th percentile value are assumed to be exceeding a safe and reasonable speed. So, it is necessary to identify 15 th percentile, 50th percentile, and 85th percentile at straight and curved road. The results of the percentile speed were calculated by using Minitab software.

For straight stretch arterial road, the 15 th percentile speed was 69.1 $\mathrm{km} / \mathrm{h}$ and the 85 th percentile speed was $96.2 \mathrm{~km} / \mathrm{h}$ (figure 2). The 85th percentile speed can be used to impose speed limit or overtaking distances as it is assumed to be the highest safe speed for a roadway section, and the 15 th percentile speed shows the slower vehicles whose speed may be 
Noor Hafiza Mohd Maksid and Abdul Azeez Kadar Hamsa

Evaluating The Effects of Road Geometrical Design Towards Spot Speed Distribution on Arterial Road

causing interferences within the traffic stream. So, the design speed for arterial road with straight stretch at the selected area at MRR2 shall be limited to $96 \mathrm{~km} / \mathrm{h}$ and vehicles should travel at least $69 \mathrm{~km} / \mathrm{h}$ to allow smooth traffic stream. Figure 3, on the other hand, shows the results for arterial road with curvature where the 15th percentile speed was $60.4 \mathrm{~km} / \mathrm{h}$ and the 85th percentile speed was $85.4 \mathrm{~km} / \mathrm{h}$. For arterial road with curvature, a speed limit of $85 \mathrm{~km} / \mathrm{h}$ should be imposed and vehicles should travel more than $60 \mathrm{~km} / \mathrm{h}$ so that they would not cause interferences to the traffic stream.

From the overall results, it is obvious that every single value of speed that was calculated for both road stretches are different from each other. The speed characteristics at straight road stretch were higher than curved road stretch except for the modal speed. Looking at the speed characteristics at the two road stretches, it is obvious that the vehicles at straight road were traveling at higher speed than curved road.

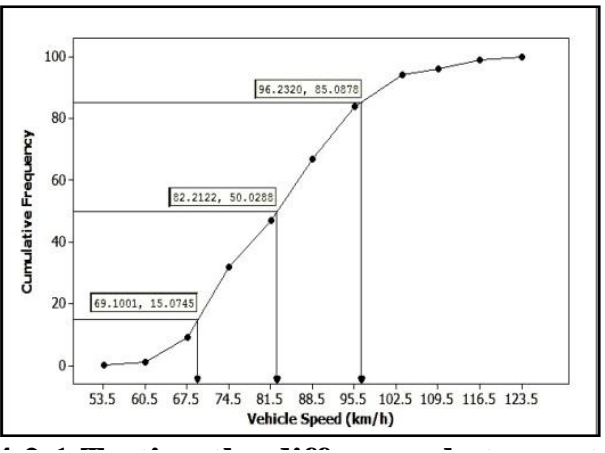

Figure 2 : Cumulative frequency graph with $15^{\text {th }}, 50^{\text {th }}$ and $85^{\text {th }}$ percentiles (for arterial road with

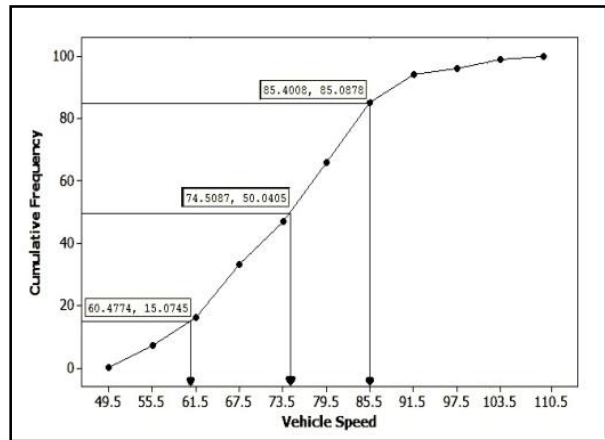

Figure 3: Cumulative frequency graph with 15th, 50th and 85th percentiles (for arterial road with curvature)

Two-sample t-test was used to determine whether there exists any significant difference between the mean of two independent samples statistically. The results would explain whether there exists any difference in spot speed between straight and curved arterial road stretch. Prior to t-test, Lavene's test was carried out to verify whether the variance of the variables is equal or not. The results show that F-value is 1.12 and the significance value $(0.287)$ is greater than the critical value 0.05 . So, it is safe to conclude that the variances for each group are equal. The t-test was conducted by using Minitab. Samples, mean, and standard deviation were filled in into Minitab prior to the calculation of the t-test. Table 3 shows the results of the t-test. 
PLANNING MALAYSIA

Urban Planning and Local Governance

Table 3: Result of t-test from Minitab

\begin{tabular}{|l|c|c|c|c|c|c|c|c|}
\hline & \multicolumn{2}{|c|}{$\begin{array}{c}\text { Levene's } \\
\text { test }\end{array}$} & \multicolumn{3}{c|}{ t-test for equality of means } & \multicolumn{2}{c|}{$95 \%$ confidence } \\
\hline & F & Sig. & t & df & Sig & $\begin{array}{c}\text { Estimate for } \\
\text { difference }\end{array}$ & Lower & Upper \\
\hline Equal $^{*}$ & 1.12 & .287 & 5.41 & 198 & .000 & 9.55 & 6.07 & 13.03 \\
\hline & \multicolumn{8}{c|}{ Source: Result from Minitab (2011) } \\
* Equal variances assumed
\end{tabular}

Table 3 shows that at $95 \%$ confidence interval, the sample mean is 6.07 and 13.03 , which means it is $95 \%$ confident that the mean difference between straight road and curved road would fall between 6.08 (lower limit) and 13.03 (upper limit).

The t-test results show that the p-value is less than the 0.05 (in this case it is 0.00). It shows that there exists statistical significance difference in the mean speed between straight and curved road stretches. In other words, the speed of the vehicles at straight and curved road stretches is not equal. The differences in the mean speed of the vehicles at these two stretches were statistically significant. It can be concluded that the curved roads are an effective measure in reducing the speed of the vehicles. However, the extent to which the vehicles can reduce speed is actually depends on the design of the curved road segments.

\section{DISCUSSION AND RECOMMENDATIONS}

From the spot speed analysis, it was found that vehicles were traveling slower along curved road than straight road. The mean speed along straight road was $83.42 \mathrm{~km} / \mathrm{h}$ and that of curved road $73.92 \mathrm{~km} / \mathrm{h}$. Collins (2008) also identified that drivers, on average, would drive fast on a straight open road, followed by a straight road in bad weather, a bendy open road, a bendy road in bad weather, a straight road in the dark and, finally, a closed bendy road. The statistical significance test to determine the difference between the mean speeds of two independent samples was carried out by t-test analysis. From the results, the p-value is 0.000 , which is less than 0.05 and it defines that the difference between the two mean speeds is statistically significant. It shows that the existence of curve alignment at a road stretch can reduce the speed of the vehicles. In term of the percentile speed, it is mentioned in the literature, that the vehicles observed in the lower 15 percent are considered to be traveling unreasonably slow and those observed above the 85th percentile are assumed to be exceeding a safe and reasonable speed. The 
Noor Hafiza Mohd Maksid and Abdul Azeez Kadar Hamsa

Evaluating The Effects of Road Geometrical Design Towards Spot Speed Distribution on Arterial Road

85th percentile speed of the straight road at MRR2 was $96 \mathrm{~km} / \mathrm{h}$, whereas at curved road it was $85 \mathrm{~km} / \mathrm{h}$. As 85 th percentile speed is used to impose speed limit because it is assumed to be the highest safe speed for roadway section, so current speed limit $(80 \mathrm{~km} / \mathrm{h})$ at MRR2 is considered low. The theory behind this is that drivers usually travel at speed that is reasonable and prudent for a given roadway segment, and they also usually careful about the speed limit. So, 85th percentile could be a guideline in setting up the speed limit as this speed is considered safe and reasonable under ideal conditions of the road. In line with this context, the results of this study are considered valid because as a vehicle approaches a curve, it is expected that the drivers, obviously, reduce the speed of their vehicles to an appropriate speed to safely negotiate the curve (Melendy, 2008).

The outcomes of this study can be used as a reference to assist the practitioners towards adopting best practice in highway geometric design and planning. As roadway is an important element in town planning, recommendation and measures to improve speed limit and enforcement is essential. Few recommendations are drawn from this study: the current speed limit should be revisited to determine an appropriate speed limit based on the $85^{\text {th }}$ percentile speed; strict enforcement in reducing vehicles traveling at high speed should be imposed; and improvement on speed reducing measures should be introduced. For the enforcement, traffic cameras should preferably be installed to monitor vehicles' compliance with speed limits. Other than that, the drivers can be educated through seminars, forums, and campaigns on the impacts and risks of driving at more than the stipulated speed limits. The same approach could be applied to the drivers that traveled below the 15th percentile speed as they might make other drivers feel inconvenient. Education and public initiatives can make positive contributions to safe driving and fewer road casualties. In addition, it is recommended to add speed reducing measures, for instance, rumble strips and speed limit sign, especially well before approaching the curved road stretches to warn the drivers about the presence of curved road paths for them to reduce the speed of their vehicles. 
PLANNING MALAYSIA

Urban Planning and Local Governance

\section{CONCLUSIONS}

Speed is one of the traffic operational elements that should be considered in the design of the road geometrics. The safe allowable speed limit will make vehicles to travel in an orderly and safe manner. It is noticeable, however, the number of accidents especially along the major roads increases over the years because of vehicles traveling at higher than the posted speed limit. This study analyses the effect of road geometrical design in combating the speed of the vehicles especially along arterial road. Two different road alignments, one representing straight road path and other curved road stretch were selected. The road geometrical elements and spot speed was measured at each of the selected road stretches.

The geometrical design of the road was found to be almost identical along straight and curved arterial road stretches. The effects of road geometrical design on the speed of the vehicles show that the differences in road geometrical design would directly affect the speed of the vehicles. The difference in the mean spot speed along straight and curved road stretches was tested for statistical significance by using t-test. The results show that the speed of the vehicles at curved road stretches was lower than straight road. It indicates that the introduction of curve alignment along the arterial road can be effective to arrest the speed of the vehicles. Finally, recommendations to reduce the speed of the vehicles were drawn. Some of the recommendations include: revisiting the current speed limit to determine an appropriate speed limit based on the $85^{\text {th }}$ percentile speed; imposing strict enforcement in reducing vehicles traveling at high speed; and improving speed reduction measures especially before the curved road alignment. It is important to take note that road planning is one of the important factors in reducing the number of road accidents. The study findings highlight that the introduction of curved road alignment along road network can reduce the speed of the vehicles and hence make the road safe for the road users whenever negotiating curved road alignments. However, the design of the curved road alignment should be made depending on the safe speed limit of the road. When planning road network, the utmost priority on road geometrical elements should be given to make the road safe for the road users. 
Noor Hafiza Mohd Maksid and Abdul Azeez Kadar Hamsa

Evaluating The Effects of Road Geometrical Design Towards Spot Speed Distribution on Arterial Road

\section{REFERENCES}

Ashley, C. (1994) Traffic and Highway Engineering for Developments. 1st Edition, Oxford, UK: Blackwell Scientific Publications, Bartlett School of Planning.

Bateman, John Henry (1948) Introduction to highway engineering: a textbook for students of civil engineering. New York: J. Wiley \& Sons.

Chen, et.al. Integrated safety speed model for curved roads, F2010-SC-0-25, Retrieved from http://www.fisita.com/education/congress/sc10/fisitasco25.pdf

Currin, Thomas R. (2001) Introduction to traffic engineering: a manual for data collection and analysis, Pacific Grove, Calif.: Brooks/Cole.

Eleni Petridou and Maria Moustaki (2000) Human factors in the causation of road traffic crashes, European Journal of Epidemiology, 16: 819-826.

Emma Collins (2008) Rural road safety - a question of speed?, Transport Research Institute, Napier University.

Garber, Nicholas J. (2001) Traffic and highway engineering, Pacific Grove, CA: Brooks/Cole Pub. Co., 1st Edition.

Herrstedt L and Griebe P (2001) Safer signing and marking of horizontal curves on rural roads, Traffic Engineering and Control, March 2001 pp 82-87, London.

Hobbs, F. D. (1967) Traffic engineering, Oxford: New York Pergamon Press.

Khanna, S.K (2001) Highway engineering, 8th edition, Roorkee; Nem Chand \& Bros.

Mannering, F. L. (2005) Principles of highway engineering and traffic analysis, 3rd edition, Hoboken, NJ: Wiley.

Melendy, L. (2008) Signs for curves and turns, Retrieved from www.techtransfer.berkeley.edu/newsletter/08-2/signs-for-curves-and-turns.php

Ministry of Works, A guide on geometric design of roads, Road Department Division, Public Works Department Malaysia, 2011.

Ministry of Transportation of P.R. China "Statistical yearbook on road traffic accidents of China (2008)", Ministry of Transportation of P.R. China, Beijing, April 2009.

Mohamed, D. (1993) Pengenalan tinjauan dan analisis lalulintas, Kuala Lumpur: Dewan Bahasa dan Pustaka.

Moore VM, Dolinis J, Woodward AJ (1995) Vehicle speed and risk of a severe crash, Epidemiology, 6: 258-262.

Roess R., Prassas E., and McShane W. (2004) Traffic Engineering, Prentice Hall, Englewood Cliffs, N.J., 3rd. Edition.

Rune Elvik, Peter Christensen, Astrid Amundsen (2004) Speed and road accidents: an evaluation of the Power Model, TOI Report 740/2004, Oslo.

Sung-Joon Hong and Takashi Oguchi (2005) Evaluation of highway geometric design and analysis of actual operating speed, Journal of the Eastern Asia Society for Transportation Studies, Vol. 6, pp. 1048-1061.

Texas Department of Transportation, Procedures for establishing speed zones, April 2012. 